\title{
Brain Drain in Maryland: Exploring Student Movement from High School to Postsecondary Education and the Workforce
}

Amber Bloomfield, Bess A. Rose, Alison M. Preston, and Angela K. Henneberger

\author{
About the Author \\ Amber Bloomfield is with the University of Maryland, \\ College Park. Bess A. Rose, Alison M. Preston, and \\ Angela K. Henneberger are with the University of \\ Maryland, Baltimore.
}

\section{Acknowledgments}

The research reported here was funded in part by the Maryland Longitudinal Data System (MLDS) Center. The authors are grateful for the data, technical, and research support provided by the MLDS Center and its agency partners. The views and opinions expressed are those of the authors and do not necessarily represent the views of the MLDS Center or its agency partners. This article is based on a research presentation and report created for and published by the MLDS Center.

The authors would also like to thank the staff in the Office of Institutional Research, Planning, and Assessment at University of Maryland, College Park,

The AIR Professional File, Fall 2020

Article 151 for their support and for guidance and feedback provided regarding this research.

\section{Abstract}

Brain drain — the movement of high school and college graduates out of state for employment-is a concern for state policymakers. This study focuses on brain drain of students who graduate from high school in Maryland. Using data from the Maryland Longitudinal Data System and applying propensity score matching to control for differences between the groups, we evaluated the degree to which brain drain exists in Maryland, and which students are likely to contribute to brain drain. Findings indicate that brain drain does exist in this state: students who graduated from a Maryland high school and who attended college out of state were less likely to return to Maryland to join the workforce compared to students who remained in state for college. Additionally, higher-achieving students were more likely to be lost to brain drain.

Keywords: brain drain, propensity score matching, student migration

https://doi.org/10.34315/apf1512020

Copyright (c) 2020, Association for Institutional Research 


\section{INTRODUCTION}

States invest significant funds in public school systems in an effort to support students and prepare them for success. One of the direct returns on the investment in public education would take the form of in-state workforce participation (Winters, 2015). Researchers call the loss of in-state high school and college graduates to other states brain drain, and it is a concern for state policymakers (Kelchan \& Webber, 2018; Zhang \& Ness, 2010). Recently, many states have invested in state-wide merit scholarship programs designed to encourage students who have strong potential to graduate from a state higher education institution and so ultimately bolster the state's educated workforce (Zhang \& Ness, 2010).

Brain drain can occur at two transition points-instate high school students can be lost to out-ofstate colleges or in-state college students can be lost to the out-of-state workforce. To understand the big picture of the brain drain phenomenon, it is important to consider student migration (i.e., movement of students out of their state of residence) at both transition points, and to follow students from high school through college and then into the workforce. However, prior research that takes this approach is limited.

In this study, we used data from the Maryland Longitudinal Data System (MLDS) to examine the movement of Maryland public high school graduates to college and then to the Maryland workforce. First, we examined the student characteristics that were associated with selection into a Maryland college compared to an out-of-state college. Second, we used propensity score matching to examine the role of out-of-state college attendance on the likelihood to return to Maryland for the workforce. Third, we examined the student characteristics of out-of-state college graduates who did return to Maryland for the workforce to identify the type of student who is most likely to be lost to brain drain.

A clear understanding of the migration patterns of students and the motivations behind student migration is important for researchers, policymakers, and other stakeholders to develop and implement programs designed to encourage student retention and eventual workforce participation. Students who attend college can decide to stay in their state of residence or attend college in another state, and their decision may rest on a variety of factors such as cost, institutional characteristics, and future employment prospects (Zhang \& Ness, 2010). It is generally expected that students will examine the options and make selections according to rational choice theory, which contends that people arrive at a decision by examining all the options then selecting the option that best allows goal attainment according to a set of criteria (Finn \& Darmody, 2017). An understanding of student mobility patterns can help researchers determine the criteria commonly associated with students' college attendance decisions, and policymakers can use these criteria to implement programs or policies designed to increase the ability for in-state institutions to meet those criteria.

Human capital theory also asserts that people make important life decisions, such as the decision of whether to attend college and, if so, which college to attend, by examining the options and selecting the one best suited for obtaining the goal in mind. In this case, the goal is always the increase of the individual's human capital (i.e., abilities, education, and training) in order to improve the individual's 
outcome in the labor market (Heller \& Rasmussen, 2002). Students will choose to educate themselves where they can find the best balance of cost and credentialing in order to build their human capital to enter the workforce in a position with the highest benefit, regardless of geography. From this human capital perspective, state policymakers are also interested in how individuals improve themselves for the job market through education. It follows logically that if a state spends public funds to support an education or training program for a student, the state wants that student to enter that particular workforce and generate income that returns to the state at the highest rate possible. Students who are educated using public funds and who then leave the state for college or employment can be viewed as losses of state resources.

\section{RELATED LITERATURE AND HYPOTHESES}

\section{Brain Drain from High School to College}

The first major transition point for a college-bound student involves the decision of where to attend college. There are many considerations involved, and choosing to go to an out-of-state college is a function of the available institutional opportunities and geographic characteristics of both the original state and the destination state (Cooke \& Boyle, 2011). States with the highest rates of brain drain between high school and college are smaller states that are densely populated, such as Maryland, or larger states that are densely populated, like Illinois (Cooke \& Boyle, 2011). States that are less densely populated, such as Pennsylvania and Indiana, tend to attract students at higher rates, potentially due to their proximity to high-density states (Cooke \& Boyle,
2011). The variation in states in terms of geographic size, population, and number and quality of higher education institutions means that considering student migration state by state provides a more accurate picture of the brain drain phenomenon than would a nationwide estimate alone. Eleven states reported a net loss of first-time degree- or certificate-seeking students at 4-year degreegranting public institutions in 2014 (U.S. Department of Education, 2015).

\section{Brain Drain from College to the Workforce}

Following college, students seeking employment can either join the workforce in the same state as their college or move to a different state for work. Kodrzycki (2001) reported that approximately 30\% of college graduates in the National Longitudinal Survey of Youth relocate to a different state within 5 years of graduation. A more recent analysis using Linkedln alumni profiles found that 58\% of 4-year college attendees had relocated to a different metropolitan area than that of their college (Rothwell, 2015). States that tend to have larger student loss rates either have large rural areas, such as lowa, or border large cities in other states, as is the case with Delaware's proximity to Philadelphia (Kelchan \& Webber, 2018). Overall, states in the South and the West are more likely to see gains from student migration while states in the Northeast and Midwest are more likely to see losses (Kelchan \& Webber, 2018).

Relocation decisions are influenced by personal characteristics as well as by state economies, population, amenities, and whether the student has a history of moving across state lines as a child (Kodrzycki, 2001). Recent nationally representative 
findings indicated that students who were more likely to leave the state of college attendance had attended highly selective institutions, had applied to multiple institutions, or were grant recipients (Ishitani, 2010). Students who were more likely to stay in the same state after college attendance were more often Hispanic or had attended college in states with a higher gross domestic product (Ishitani, 2010).

\section{Brain Drain from High School to College to the Workforce}

The study of brain drain from high school to college to the workforce has been approached using multiple data sets at corresponding points in time (e.g., Groen, 2004), or by using one longitudinal data set that follows a sample of students across both transition points (e.g., Perry, 2001). These studies consistently found that students who attend college in their home state are more likely to work in their home state when compared to those who attend an out-of-state college. Groen (2004) investigated brain drain using two separate longitudinal data sets, both including students who initially enrolled in a 4-year college in the 1970s: the Mellon Foundation's College and Beyond data set (C\&B, 1976 cohort) and the National Longitudinal Study of the High School Class of 1972 (NLS-72). Controlling for gender and SAT score, Groen (2004) found that $48 \%$ of students in the C\&B sample who attended college in their original state of residence versus 39\% of students who attended college out of state; comparable percentages in the NLS-72 sample were 62\% versus $52 \%$.

Perry (2001), investigating brain drain using data from the NCES Baccalaureate and Beyond Longitudinal Study, found that $83 \%$ of in-state graduates lived in their original state of residence, compared to only $52 \%$ of out-of-state graduates. Perry also found that the majority of college graduates in her sample had graduated from a college in their original state of residence (i.e., most college graduates were in-state students). In addition, students who attended an in-state college were more likely to live in the state of the college from which they had graduated than were students who attended an out-of-state college (Perry, 2001).

It is important to note that both Groen (2004) and Perry (2001) examined students' state of residence, and not employment status within the state. For the purpose of studying brain drain, state policymakers would be interested in students' eventual contribution to the workforce and ability to support the economy of the state, not just where they reside. Much of the research that does address employment outcomes centers on the results of state-sponsored scholarship programs intended to encourage students to stay in state for college (e.g., Harrington et al., 2016; Hawley \& Rork, 2013; Hickman, 2009; Sjoquist \& Winters, 2013), rather than providing the general overview of student migration necessary to fully understand the trends. The current literature generally focuses on either the transition from high school to college, or the transition from college to workforce, possibly due to the difficulty of obtaining linked longitudinal data over time. While some research has been able to longitudinally investigate the full path of brain drain, these studies are limited by considering only college graduates (Perry, 2001), or examining employment location after a considerable time gap (Groen, 2004). A further limitation of prior research has been the lack of sufficiently rigorous approaches to control for preexisting differences between students who enrolled in state and those who enrolled out of 
state (e.g., SAT scores, marital status). Those studies that were able to track students from high school through college and into the workforce had limited information about these students and so could not control for potential differences between those who chose an out-of-state institution and those who chose an in-state institution. Groen (2004) investigated the role of SAT scores in brain drain patterns, but did not investigate other likely relevant characteristics such as race or socioeconomic status. Perry (2001) did not take into account student characteristics when examining brain drain patterns. This gap is of concern because the same factors that may lead a student to select an in-state institution might also affect their likelihood of attaining work in their home state. We address these limitations by investigating the relationship between location of the higher education institution (out of state versus in state) and the likelihood that students return to their home state's workforce, taking into account differences in demographic, academic achievement, and high school characteristics.

\section{The Current Study}

In Maryland there is evidence of notable student migration between high school and college as well as between college and the workforce. In 2014 Maryland reported a net loss of 8,881 students between high school and college, the fifth-largest net loss in the country (U.S. Department of Education, 2015). For the second transition point, from college to the workforce, data from the Integrated Public Use Microdata Series (IPUMS-USA) indicated that Maryland had a net migration rate for college graduates under age 40 of approximately $1 \%$ from 2000 to 2015 (Bui, 2016). This means that there was an approximately $1 \%$ positive difference in the number of college graduates under age 40 who moved to Maryland compared to the number who left. While this particular study indicated a positive net migration rate, there is still a considerable amount of flow in and out of Maryland in the time frame included.

Our study aims to address the limitations of prior research by applying a propensity score matching analysis approach to a unique longitudinal high school-college-workforce extant data set to analyze brain drain at both transition points in Maryland. Data from the MLDS link high school, college, and workforce records across multiple years for Maryland public high school attendees. Thus, this study can examine the same group of students at both transition points. This study answers the following research questions:

1| Do Maryland public high school graduates who enroll in out-of-state colleges differ from those who enroll in in-state colleges with regard to achievement or demographic variables?

2| Does the location of college enrollment change the likelihood of working in Maryland (i.e., is there brain drain in Maryland)?

3| Do students who enroll in out-of-state colleges and go on to work in Maryland differ from students who enroll in out-of-state colleges and do not go on to work in Maryland, or, put another way, who is lost to brain drain in Maryland? 


\section{METHOD}

The data used for these analyses are from the MLDS, which contains linked longitudinal data from multiple sources. ${ }^{1}$ The Maryland State Department of Education provides data for public pre-K-12 students and schools. The Maryland Higher Education Commission provides data for Maryland public and private colleges and students. Out-of-state college enrollment and degree information is obtained through the National Student Clearinghouse. The Maryland Department of Labor Licensing and Regulation provides data for employees in the state who work for employers who are subject to Maryland's unemployment tax law. The workforce data do not include information for federal employees, military employees, individuals who are self-employed, or private contractors. The latest workforce data available at the time of these analyses were for fiscal year $2016 .^{2}$

All Maryland public high school students who graduated in academic year 2008-9 were identified. ${ }^{3}$ We focused on graduates whose first year of college enrollment occurred in 2010, excluding those who enrolled in college in 2011 or later, to allow 6 years for the completion of undergraduate education within the time span of the available data (through 2017). This 6-year graduation window is considered adequate for reporting and is a widely used metric for reporting undergraduate graduation rates (Engelmyer, 2019). We further focused on those students whose initial enrollment was in a 4-year institution, whether public or private. Finally, to focus on the role of in-state versus out-of-state college undergraduate enrollment in the likelihood of joining the Maryland workforce after undergraduate education, we excluded the data of students who were still enrolled as undergraduates in 2016.
Ultimately, we retained data from 29\% of the 2009 Maryland high school graduates for these analyses. The group of students included differs in several ways from other 2009 Maryland high school graduates. For instance, the students retained for analyses tended to have stronger academic indicators than students whose data were excluded for one or more reasons. In addition, students retained for analyses were less likely to belong to minority race or ethnic groups. Table 1 shows the demographic and achievement variables for the retained and excluded students.

\section{MEASURES}

In-state and out-of-state college enrollment was measured by examining the first record of college enrollment at a 4-year public or private institution. Covariates included demographic variables (e.g., race and gender), academic achievement indicators (SAT scores, high school GPA), and characteristics of the high schools from which the students graduated (e.g., the percentage of students in the school eligible for free and reduced-price meals). Note that students who had Advanced Placement scores must have opted to take the associated Advanced Placement test; students who took an Advanced Placement courses but did not take the test would not have data for Advanced Placement. Due to the small number of students in some race categories, groups were collapsed into underrepresented minorities (URMs) (Black or African American, Hispanic or Latino, American Indian or Alaska Native, Native Hawaiian and Other Pacific Islander, two or more races) and non-URMs (White, Asian). These categories are consistent with the National Institutes of Health (NIH) definition of URM in sciences (NIH n.d.). Workforce participation in Maryland was

1. For more information, visit https://mldscenter.maryland.gov/.

2. For more information, visit http://www.studentclearinghouse.org/.

3. In future references to enrollment and graduation years, we indicate the academic year. For instance, 2009 corresponds to the academic year 2009 , which began in the fall of 2008 . 
Table 1. Demographic and achievement variable values for students whose data were included in the analyses and those whose data were not included

Data not included

$(N=41,461)$

High school program completion: Met requirements for

Approved career and technology program

Approved USM and occupational program

Approved USM

Noncompleter

Other high school completions

Missing

Gender

Male

Female

Race

White

Black

Asian

Native Hawaiian and Other Pacific Islander

American Indian or Alaska Native

Two or more races

Ethnicity

Hispanic or Latino

Not Hispanic or Latino

Highest AP test score

Highest IB diploma test score

Highest IB grade test score

Highest IB diploma proficiency

Highest IB grade proficiency

PSAT verbal

$\begin{array}{lr}13 \% & 2 \% \\ 10 \% & 9 \% \\ 46 \% & 78 \% \\ 2 \% & <1 \% \\ 28 \% & 11 \% \\ <1 \% & <1 \%\end{array}$

$50 \%$

$44 \%$

$50 \%$

$56 \%$

$57 \%$

$59 \%$

$37 \%$

$31 \%$

$4 \%$

$9 \%$

$<1 \%$

$<1 \%$

$<1 \%$

$<1 \%$

$1 \%$

$<1 \%$

$\begin{array}{rr}9 \% & 3 \% \\ M=2.7 ; S D=1.4 & M 7 \% \\ M=26.0 ; S D=6.4 & M=28.4 ; S D=6.4 \\ M=12.3 ; S D=13.7 & M=17.30 ; S D=14.8 \\ M=3.34 ; S D=0.9 & M=3.55 ; S D=0.9 \\ M=4.85 ; S D=1.3 & M=5.20 ; S D=1.2 \\ M=41.01 ; S D=11.0 & M=50.94 ; S D=10.9\end{array}$




\begin{tabular}{|c|c|c|}
\hline PSAT writing & $M=40.54 ; S D=10.8$ & $M=50.58 ; S D=11.1$ \\
\hline PSAT math & $M=41.86 ; S D=11.4$ & $M=52.48 ; S D=11.8$ \\
\hline Took the ACT/SAT & $50 \%$ & $94 \%$ \\
\hline Took at least one IB exam & $1 \%$ & $4 \%$ \\
\hline Took the PSAT & $60 \%$ & $80 \%$ \\
\hline Took at least one AP exam & $20 \%$ & $70 \%$ \\
\hline SAT/ACT math & $M=458.3 ; S D=118.4$ & $M=547.2 ; S D=117.4$ \\
\hline SAT/ACT verbal & $M=455.5 ; S D=111.0$ & $M=537.8 ; S D=109.4$ \\
\hline SAT/ACT writing & $M=450.6 ; S D=108.3$ & $M=536.6 ; S D=109.8$ \\
\hline \multicolumn{3}{|l|}{ Met rigorous high school program requirements for } \\
\hline Foreign language & $33 \%$ & $72 \%$ \\
\hline Math & $24 \%$ & $61 \%$ \\
\hline Science & $12 \%$ & $39 \%$ \\
\hline Advanced technology education & $7 \%$ & $8 \%$ \\
\hline Completed high school with a cumulative GPA $\geq 3.0$ & $26 \%$ & $70 \%$ \\
\hline
\end{tabular}

Note: USM = University System of Maryland; AP = Advanced Placement; IB= International Baccalaureate. Students whose data were included in analyses graduated from a Maryland public high school in 2009, enrolled at a 4-year college in 2010, and were not enrolled in any undergraduate program in 2016. Where available, ACT Reading and ACT English scores are summed, then converted into SAT verbal scores.

coded if the student had at least one workforce record that occurred in the fourth fiscal quarter of the same calendar year as their last year of undergraduate college enrollment, or any quarter of a later year. This approach explicitly excluded the summer quarter following the last college enrollment record, which might indicate temporary summer employment prior to enrolling in graduate school or seeking more-permanent employment. Graduate students who did not have any concurrent employment were classified as students who did not seek employment in Maryland following graduation from an undergraduate program.

\section{ANALYSES}

\section{Missing Data}

Data, particularly achievement indicators like SAT subtest scores, were missing for several of the students in our sample. We applied multiple imputation to use the patterns among existing data in the data set to extrapolate missing data values (Sinharay et al., 2001), creating 20 complete data sets. In conducting imputation, we assumed that high school information, such as the proportion of students eligible for free and reduced-price meals 
Table 2. Demographic and achievement characteristics for Maryland public high school graduates who enrolled in 4-year colleges outside of and in Maryland

Outside of Maryland

High school program completion: Met requirements for

Approved career and technology program

Approved USM and occupational program

Approved USM

Noncompleter

Other high school completions

Missing

Gender

Male

Female

Race

White

Black

Asian

Native Hawaiian and Other Pacific Islander

American Indian or Alaska Native

Two or more races

Hispanic or Latino

Highest AP test score

Highest IB diploma test score

Highest IB grade test score

Highest IB diploma proficiency

Highest IB grade proficiency
$(\mathrm{N}=8,145)$

In Maryland

$(N=8,790)$

$\begin{array}{cc}2 \% & 2 \% \\ 8 \% & 11 \% \\ 78 \% & 77 \% \\ <1 \% & <1 \% \\ 11 \% & 10 \% \\ <1 \% & <1 \%\end{array}$

$43 \%$

$45 \%$

$57 \%$

$55 \%$

$63 \%$

$55 \%$

$30 \%$

$33 \%$

$6 \%$

$12 \%$

$<1 \%$

$<1 \%$

$<1 \%$

$<1 \%$

$<1 \%$

$<1 \%$

$3 \%$

$4 \%$

$$
\begin{array}{r}
M=3.5 ; S D=1.4 \\
M=29.7 ; S D=6.2 \\
M=17.1 ; S D=15.5 \\
M=3.6 ; S D=0.9 \\
M=5.3 ; S D=1.2
\end{array}
$$$$
M=3.4 ; S D=1.4
$$$$
M=26.9 ; S D=6.3
$$$$
M=17.6 ; S D=13.8
$$$$
M=3.4 ; S D=0.9
$$

$M=5.1 ; S D=1.2$ 


\begin{tabular}{|c|c|c|}
\hline PSAT verbal & $M=51.4 ; S D=11.3$ & $M=50.5 ; S D=10.5$ \\
\hline PSAT writing & $M=51.0 ; S D=11.6$ & $M=50.2 ; S D=10.5$ \\
\hline PSAT math & $M=52.7 ; S D=12.1$ & $M=52.2 ; S D=11.5$ \\
\hline Took the ACT/SAT & $94 \%$ & $95 \%$ \\
\hline Took at least one IB exam & $4 \%$ & $3 \%$ \\
\hline Took the PSAT & $82 \%$ & $82 \%$ \\
\hline Took at least one AP exam & $70 \%$ & $68 \%$ \\
\hline SAT/ACT math & $M=552.0 ; S D=118.1$ & $M=542.7 ; S D=116.5$ \\
\hline SAT/ACT verbal & $M=542.8 ; S D=113.7$ & $M=533.3 ; S D=105.1$ \\
\hline SAT/ACT writing & $M=542.3 ; S D=114.6$ & $M=531.2 ; S D=105.0$ \\
\hline \multicolumn{3}{|l|}{ Met the rigorous high school program requirements for } \\
\hline Foreign language & $71 \%$ & $73 \%$ \\
\hline Math & $61 \%$ & $62 \%$ \\
\hline Science & $38 \%$ & $39 \%$ \\
\hline Advanced technology education & $8 \%$ & $8 \%$ \\
\hline Completed high school with a cumulative GPA $\geq 3.0$ & $69 \%$ & $71 \%$ \\
\hline
\end{tabular}

Note: USM = University System of Maryland; AP = Advanced Placement; IB= International Baccalaureate. Where available, ACT Reading and ACT English scores are summed, then converted into SAT verbal scores.

at a given high school, was missing at random and conditional on known variables; we also assumed that this information could be reasonably imputed. However, other information, such as SAT scores, could be missing data or might indicate that the student did not take the SAT. To handle this type of missingness, we first generated variables indicating whether a student had taken the PSAT or SAT/ ACT. Subtest scores were then imputed only if the indicator variable for that test was positive; if the person did not have a score on any SAT or ACT subtest, no scores were imputed (approximately 6\% of the sample). ${ }^{4}$ A similar process was followed for scores on the PSAT subtests (approximately 18\% of students were missing all PSAT subtest scores). No scores were imputed for Advanced Placement or International Baccalaureate tests, since taking one of these tests does not indicate that a person has taken others. 


\section{Analytic Approach}

In order to estimate the effect of location of college on likelihood of joining the Maryland workforce after college, we applied a propensity score matching approach (Austin 2011; Rosenbaum \& Rubin, 1983). ${ }^{5}$ Propensity score matching is used to impose a quasi-experimental design onto nonexperimental data sets (Holmes, 2013). In an experiment, random assignment of participants to conditions helps to control for the possibility of differences in extraneous variables, such as the participants' academic achievements, leading to group differences in the outcome of interest. In real extant data such relationships are likely to exist: a high school student with a higher GPA might be more likely to attend an out-of-state university because the student is more likely to receive meritbased financial aid to offset out-of-state tuition. We used propensity score matching to correct for preexisting differences between students who enrolled at a Maryland college and those who enrolled at an out-of-state college on covariates that could potentially affect the outcome. The propensity score model included all high school, demographic, and achievement covariates (see Table 2). ${ }^{6}$ We selected one-to-one matching between students in the treatment condition (out-of-state college enrollment) and students in the control condition (Maryland college enrollment) and used a greedy matching algorithm with a caliper of 0.20 and no replacement. The matching procedure was repeated for each of the imputed data sets. Due to differences in the imputed values between the data sets, the number of students in the treatment condition that could successfully be matched to students in the control condition varied slightly, yielding slightly different sizes for the resulting matched data sets (14,518-14,556; see Table 3 below).
Figure 1 shows the distribution of propensity scores between the two groups prior to matching and Figure 2 shows the distribution after matching. A comparison of Figures 1 and 2 shows sufficient overlap of propensity scores for the students who attended college in Maryland and outside of Maryland, with overlap improving in the matched sample. Figure 3 shows the standardized mean differences (SMDs) for the variables included in the propensity score model in the unmatched and matched data sets. The SMD between the treatment and the control groups was below 0.1 for all covariates in all of the 20 matched data sets, indicating that differences between the groups were negligible (Austin, 2011; Normand et al., 2001). The SMD improved in the matched data sets when compared to the unmatched data set.

Logistic regression analyses were conducted with the matched data sets to explore whether enrolling at a college outside of Maryland affected the likelihood that a Maryland high school graduate would join the Maryland workforce after college after the groups were matched on all available covariates. Coefficients and variances from these analyses were statistically combined using Rubin's (1987) pooling methodology to generate a single set of results. Follow-up descriptive analyses examined the student characteristics of students who attended college out of state and returned to Maryland to join the workforce compared to out-of-state college students who did not return to Maryland to join the workforce.

5. We used the Matching package (Sekhon, 2011) in the $R$ statistical environment (R Core Team, 2015).

6. The propensity model included the interaction between the SAT/ACT and PSAT indicator variables and the subtest scores rather than the main effect of the subtest scores (which would have resulted in the analysis excluding data from any students without SAT/ACT and PSAT scores). 
Figure 1. Distribution of propensity scores in the in-state and out-of-state groups before matching

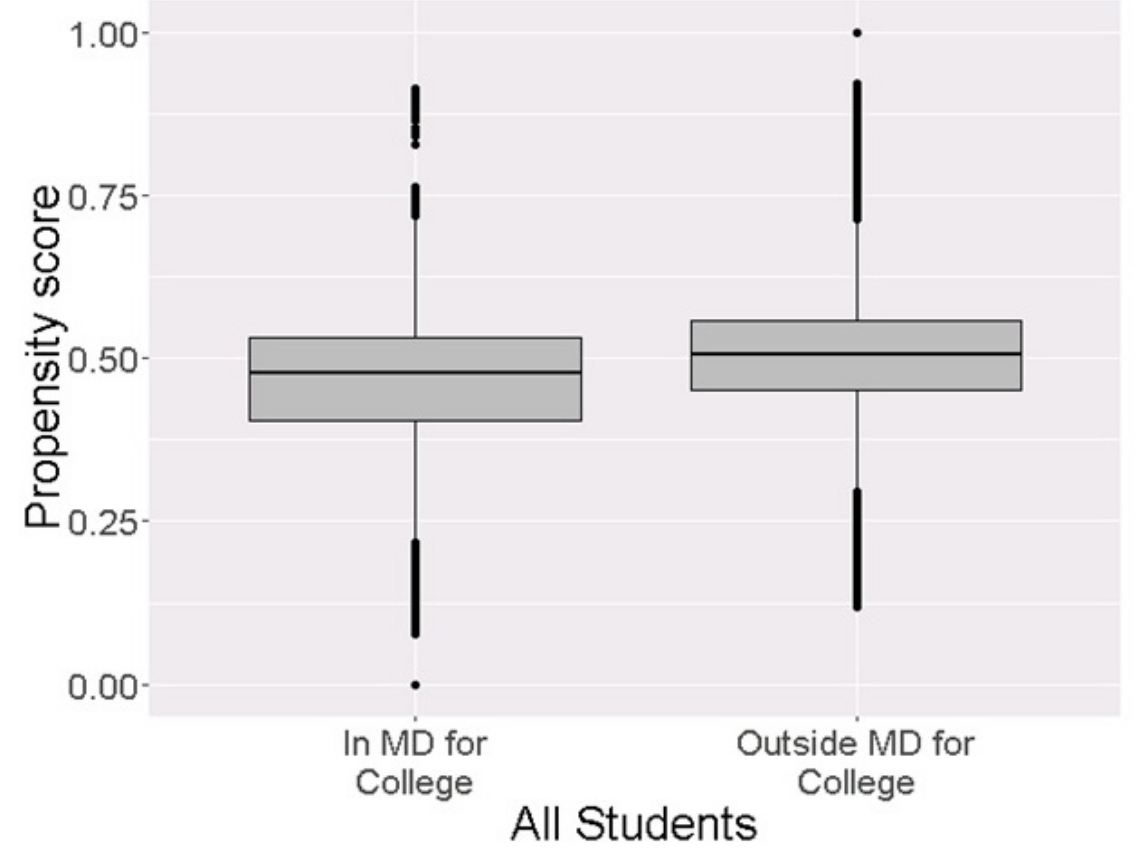

Figure 2. Distribution of propensity scores in the in-state and out-of-state groups after matching






\section{Figure 3. Standardized mean difference (SMD) on variables in the matched and unmatched}

samples

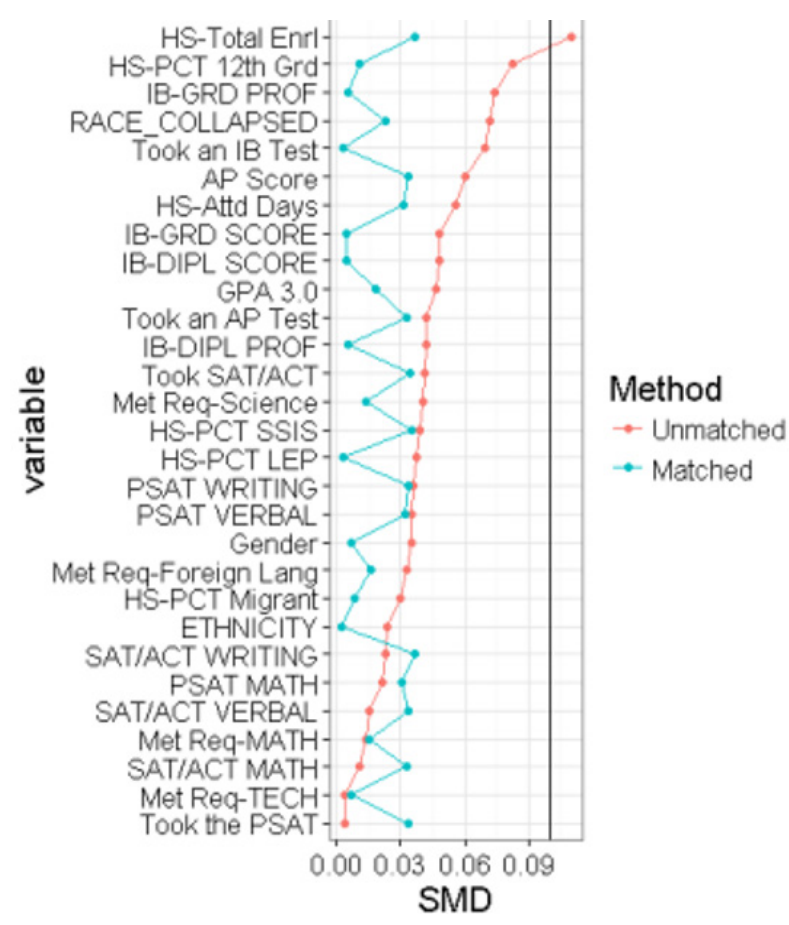

Note: HS-Total Enrl = Total enrollment in the student's high school

HS-PCT 12th Grd = Percent of the student's high school population in the 12 th grade

IB-GRD PROF = Highest proficiency level on an International Baccalaureate test

RACE_COLLAPSED = Race category (Underrepresented minority vs. Not underrepresented minority)

Took an IB test $=$ Did the student take at least one International Baccalaureate test?

AP score $=$ Highest score on an Advanced Placement test

HS_Attd Days = Number of days the student attended high school in their final year

IB-GRD SCORE = Highest score on an International

Baccalaureate test

IB-DIPL PROF = Highest proficiency on an International Baccalaureate diploma

Took SAT/ACT = Did the student take the ACT or SAT?

Met Req-Science $=$ Did the student meet the requirements for rigorous high school program completion in science?

HS-PCT SSIS = Percent of student's high school in a special education program
HS-PCT LEP = Percent of the student's high school in an English proficiency program

PSAT WRITING = PreSAT writing score

PSAT VERBAL = PreSAT Verbal score

Gender $=$ Gender

Met Req-Foreign Lang = Did the student meet the requirements for rigorous high school program completion in foreign language?

HS-PCT Migrant = Percent of the student's high school categorized as migrant

Ethnicity $=$ Ethnicity

SAT/ACT Writing = SAT or converted ACT writing score

PSAT MATH = PreSAT math score

SAT/ACT Verbal = SAT or converted ACT verbal score

Met Req-Math = Did the student meet the requirements for rigorous high school program completion in math?

SAT/ACT Math = SAT or converted ACT math score

Met Req-TECH = Did the student meet the requirements for rigorous high school program completion in advanced technology education?

Took the PSAT = Did the student take the PSAT? 


\section{FINDINGS}

\section{Comparing Maryland College Students to Out-of-State College Students}

Of the cohort of Maryland high school graduates included in the analyses, 48\% initially enrolled in a college outside of Maryland. Table 2 presents the results comparing the demographic and achievement characteristics of Maryland public high school graduates who enrolled in college in state and out of state. Students enrolled outside of Maryland were less likely to have completed course requirements for both the University System of Maryland (USM) and a career and technology program, and were less likely to be Black or Asian and more likely to be White. In terms of academic variables, such as SAT score and whether the student had taken an Advanced Placement exam, the differences between the two groups are very slight.

\section{Is There Brain Drain from Maryland?}

The descriptive statistics in Table 2 indicate that the high school graduates in the sample who enroll in an out-of-state college differ from those who enroll in an in-state college. Using propensity score matching, we matched in-state and out-of-state enrollees on the variables shown in Table 2. It was then possible to examine whether there is a difference between the two matched groups in their likelihood of appearing in the Maryland employment records after college. Table 3 presents the results of the logistic regression analyses predicting workforce participation in Maryland with out-of-state 4-year college enrollment using the full sample and the matched sample. In the sample matched on all available demographic, academic achievement, and high school characteristics, enrollment at a college outside of Maryland had a negative relationship with an individual joining the Maryland workforce following college. We can transform the log-odds (indicated by the beta weight in Table 3) into odds to understand how likely a student in the matched data set who went to an out-of-state institution was to have participated in the Maryland workforce compared to one who went to a Maryland institution: e-1.13 $=0.323$, or roughly one-third as likely. Across the matched data sets, $80 \%$ of students who enrolled at Maryland colleges had postcollege workforce records, compared to $57 \%$ of students who enrolled outside of Maryland. The coefficient size for the treatment was larger in the unmatched than the matched, indicating that propensity score matching eliminated some of the between-group differences that influenced the likelihood of joining the Maryland workforce. Even after propensity score matching, however, the relationship between location of initial college enrollment and likelihood of joining the Maryland workforce remains sizable.

\section{Who Is Lost to Brain Drain from Maryland?}

Table 4 displays the descriptive statistics for students who enrolled at a 4-year college outside of Maryland and who returned to Maryland for work, compared to students who enrolled at a 4-year college outside of Maryland and do not have Maryland employment records after college. Individuals who enrolled in college out of state and joined the Maryland workforce tended to have less-positive high school academic indicators than individuals who did not join the Maryland workforce 
Table 3. Logistic regression with 4-year college enrollment outside of Maryland predicting workforce participation in Maryland

\begin{tabular}{|c|c|c|c|c|c|c|}
\hline \multirow[b]{2}{*}{ Coefficients } & \multicolumn{3}{|c|}{$\begin{array}{l}\text { Full Sample } \\
(N=16,935)\end{array}$} & \multicolumn{3}{|c|}{$\begin{array}{l}\text { Matched Sample } \\
\qquad(N \geq 14,518)^{\star}\end{array}$} \\
\hline & Estimate & Std. Error & $p$ & Estimate & Std. Error & $p$ \\
\hline (Intercept) & 1.46 & 0.03 & $<0.001$ & 1.39 & 0.03 & $<0.001$ \\
\hline Outside of Maryland for & -1.22 & 0.04 & $<0.001$ & -1.13 & 0.04 & $<0.001$ \\
\hline College & & & & & & \\
\hline
\end{tabular}

* Sample size shown is the minimum of the range across the sets of matched data.

after enrolling in college out of state (e.g., lower SAT/ACT subtest scores). There was no difference between the two groups in the rate of enrolling in a graduate program.

\section{DISCUSSION}

This study examined the brain drain phenomenon in Maryland; specifically, we examined the characteristics of Maryland high school students who enrolled in college in state in comparison to those who enrolled in college out of state, whether those students who remained in state for college continue to remain in state for employment following graduation, and what differences exist between the two groups. The findings indicate that there is some degree of brain drain when Maryland public high school students enroll in colleges outside of Maryland. Students who enrolled in 4-year outof-state colleges were less likely to join the Maryland workforce following college when compared to Maryland public high school students who enrolled in Maryland colleges (80\% of students who enrolled at Maryland colleges had postcollege workforce records, compared to $57 \%$ of students who enrolled outside of Maryland). Furthermore, the individuals who return to the Maryland workforce after enrolling in out-of-state colleges tend to be lower-achieving students (with regard to high school achievement measures) than students who do not return to the Maryland workforce. This suggests that individuals with stronger academic indicators may be more likely to go on to employment outside of Maryland following enrollment in a college outside of Maryland than are individuals with less-positive academic indicators.

The findings from this study are generally consistent with prior research reporting brain drain from high school through college to the workforce (Groen, 2004; Perry, 2001). The majority of the Maryland public high school students in the sample initially enrolled at a Maryland institution, consistent with Hawley and Rork (2013) and Perry (2001). Also consistent with Perry (and with Groen, 2004), there was a negative relationship between enrollment in an out-of-state college and likelihood of returning to the original state of residence for employment. However, previous examinations of college graduate 
Table 4. Demographic, achievement, college attendance, and degree characteristics of Maryland public high school graduates who enrolled in a 4-year out-of-state college by whether the person worked in Maryland after college

Did not join the Maryland workforce $(N \geq 3,145)^{*}$

Count of college enrollment terms

Enrolled in a graduate program

Received a certificate

Received an associate degree

Received a bachelor's degree

Received a master's degree

Female

Underrepresented minority

Hispanic or Latino

Highest AP test score

Highest IB diploma test score

Highest IB grade test score

Highest IB diploma proficiency

Highest IB grade proficiency

PSAT verbal

PSAT writing

PSAT math

Took the ACT/SAT

Took at least one IB exam

Took the PSAT

Took at least one AP exam

SAT/ACT math
$M=9.9 ; S D=3.0$

$20 \%$

$0 \%$

$1 \%$

$75 \%$

$<1 \%$

$54 \%$

$27 \%$

$4 \%$

$M=3.7 ; S D=1.4$

$M=19.8 ; S D=15.9$

$M=19.8 ; S D=14.9$

$M=2.4 ; S D=1.9$

$M=5.4 ; S D=1.1$

$M=53.6 ; S D=11.2$

$M=53.2 ; S D=11.4$

$M=55.7 ; S D=12.2$

$96 \%$

$4 \%$

$84 \%$

$78 \%$

$M=577.6 ; S D=117.3$
Did join the Maryland workforce $(N \geq 4,109)^{*}$

$M=9.5 ; S D=3.7$

$21 \%$

$1 \%$

$3 \%$

$69 \%$

$3 \%$

$57 \%$

$35 \%$

$3 \%$

$M=3.2 ; S D=1.4$

$M=17.2 ; S D=14.0$

$M=17.2 ; S D=14.0$

$M=2.2 ; S D=1.9$

$M=4.9 ; S D=1.3$

$M=48.9 ; S D=10.8$

$M=48.5 ; S D=11.0$

$M=50.3 ; S D=11.4$

$92 \%$

$3 \%$

$80 \%$

$63 \%$

$M=526.2 ; S D=112.3$ 


\begin{tabular}{|c|c|c|}
\hline SAT/ACT verbal & $M=566.1 ; S D=112.1$ & $M=517.5 ; S D=106.4$ \\
\hline SAT/ACT writing & $M=561.8 ; S D=112.6$ & $M=516.1 ; S D=107.5$ \\
\hline $\begin{array}{l}\text { Met the rigorous high school program } \\
\text { requirements for foreign language }\end{array}$ & $77 \%$ & $69 \%$ \\
\hline $\begin{array}{l}\text { Met the rigorous high school program } \\
\text { requirements for math }\end{array}$ & $68 \%$ & $57 \%$ \\
\hline $\begin{array}{l}\text { Met the rigorous high school program } \\
\text { requirements for science }\end{array}$ & $44 \%$ & $34 \%$ \\
\hline $\begin{array}{l}\text { Met the rigorous high school program } \\
\text { requirements for advanced technology } \\
\text { education }\end{array}$ & $10 \%$ & \\
\hline $\begin{array}{l}\text { Completed high school with a cumulative } \\
\text { GPA of } 3.0 \text { or higher }\end{array}$ & $78 \%$ & \\
\hline
\end{tabular}

Note: * The samples sizes shown are the minimum of the range across sets of matched data. AP = Advanced Placement; $\mathrm{IB}=$ International Baccalaureate. These analyses include all individuals in the matched data sets who were in the treatment group (i.e., initially enrolled out of state); sample sizes shown are the minimum of the range across sets of matched data. Where available, ACT Reading and ACT English scores are summed, then converted into SAT verbal scores.

migration (Bui, 2016) reported that Maryland has a net gain with regard to the number of college graduates under 40: more graduates come into Maryland than leave. Unfortunately, it is not possible with the current data to see this positive difference, which would require access to the data of all college graduates across the United States, rather than just those who first graduated from a Maryland public high school or who attended Maryland postsecondary institutions. In other words, the results reported here indicate that brain drain occurs, but they do not speak to the sum total of postcollege individuals who join the Maryland workforce.

This study is limited in several ways. The available workforce data did not include self-employment, military service, federal employment, or independent contractors. A person who does not have workforce records following college enrollment could be unemployed, employed outside of Maryland, or employed in one of those excluded domains. To draw conclusions from differences in the number of in-state college enrollees and out-ofstate enrollees who have workforce records, it is assumed that the likelihood of being employed in jobs in those excluded domains is the same for both groups. Furthermore, the propensity scores used to match the treatment and nontreatment groups in this study were calculated based on the variables available, and it is possible that there were unmeasured confounders, or other variables related to Maryland employment that were not included. For instance, information about students' specific socioeconomic status, their parents' education level, or the students' behavior during high school (e.g., if the student had suspensions or discipline referrals) might have improved the matching process and potentially influenced the results of the outcome analysis. Finally, this study retained only 29\% of the 2009 Maryland high school graduates, and the students retained differed from 
those that were excluded on several indicators, including demographic characteristics and academic performance indicators. Therefore, the generalizability of this study is limited to students who matched the profile of included students.

\section{POLICY IMPLICATIONS}

Many states, such as Florida, Georgia, Missouri, and Texas, have adopted legislation designed to reward high-performing students with merit- or need-based assistance. These programs have differed in their impact on brain drain (Harrington et al., 2016; Hickman, 2009; Sjoquist \& Winters, 2013; Zhang \& Ness, 2010). The current study investigated the question of brain drain as it occurs at the intervention point of these kinds of programs: If a Maryland high school graduate is motivated to enroll at a Maryland college rather than an outof-state college, is that person more likely to stay in Maryland to work? The results suggest that a program that increases the likelihood of a high school graduate attending an in-state college is likely to increase the number of high school graduates who stay in the state's workforce. Furthermore, other research suggests that out-of-state high school graduates who enroll at a state's colleges will not be as likely to stay in the state postcollege as are high school graduates who stay in state for college (Perry, 2001). This implies that retaining high school graduates in state for college is more likely to benefit a state's workforce than is attracting outof-state students to its colleges. However, neither the current study nor Perry's investigation explored the types of employment held by different groups. It is possible that workers who originally live in other states tend to work at different jobs, or that students who go out of state for college and return to the original state's workforce work different jobs than those who stay in state for college and join the workforce. Furthermore, previous research suggests that programs designed to encourage in-state college enrollment may accomplish this goal but still fail to increase the number of individuals who join the state's workforce after college (Sjoquist \& Winters, 2013). A solution could involve programs that encourage in-state enrollment for specific subgroups of high school graduates for whom instate enrollment has the strongest relationship to likelihood of joining the original state's workforce.

\section{FUTURE DIRECTIONS}

To help states better understand the brain drain phenomenon and how to best mitigate its impact, future research should explore differences in rates of enrollment in public and private institutions for students who enroll at in-state versus out-of-state colleges. The approach taken to mitigate brain drain might depend on whether it is primarily students attending out-of-state private institutions who do not return to the state's workforce or primarily students attending out-of-state public institutions who do not return. A similar motivation exists for examining the location of the out-of-state institution (e.g., 250 miles or closer versus farther than 250 miles away, or colleges in specific states) and its effect on likelihood of returning to the original state's workforce after college. Future research on brain drain could also usefully investigate the types of employment held by former in-state versus out-of-state college students. It is possible that certain types of jobs tend to be held by people who went out of state for college. 


\section{CONCLUSION}

This study used linked longitudinal data from the MLDS to investigate the full brain drain process from high school to college and to the workforce. The findings indicate that brain drain does exist in Maryland: Maryland public high school students who go out of state for college are less likely to be found in the Maryland workforce than are Maryland public high school students who stayed in state for college. The findings of this study contribute to the literature on brain drain in that they provide a direct examination of how enrollment in an out-ofstate college affects the rate of joining the state's workforce while using propensity score matching to control for the differences that exist between these two groups at the outset. The demographic variables, academic indicators, and high school information available in the MLDS enabled the application of advanced statistical methods for this analysis in order to be more confident that similar groups of students, who differed only in the location of their initial college enrollment, were compared regarding their workforce outcome.

\section{REFERENCES}

Austin, P. C. (2011). An introduction to propensity score methods for reducing the effects of confounding in observational studies. Multivariate Behavioral Research, 46(3), 399-424.

Bui, Q. (2016). The states that college graduates are most likely to leave. New York Times, November 22, 2016. Retrieved September 12, 2017, from https:// www.nytimes.com/2016/11/22/upshot/the-statesthat-college-graduates-are-most-likely-to-leave.html.
Cooke, T. J., \& Boyle, P. (2011). The migration of high school graduates to college. Educational Evaluation and Policy Analysis, 33(2), 202-213.

Dorans, N. J. (1999). Correspondences between ACT ${ }^{\mathrm{M}}$ and SAT ${ }^{\circledR}$ I scores. College Board Report No. 99-1, ETS RR No. 99-2. College Entrance Examination Board, New York. Retrieved from https://www.ets. org/Media/Research/pdf/RR-99-02-Dorans.pdf.

Engelmyer, L. (2019). 2 key statistics for college cost comparison: Graduation rate and retention rate explained. College Raptor, February 21, 2019. Retrieved from https://www.collegeraptor.com/ find-colleges/articles/college-comparisons/2-keystatistics-for-comparing-colleges-graduation-rateand-retention-rate-explained/.

Finn, M., \& Darmody, M. (2017). Examining student immobility: A study of Irish undergraduate students. Journal of Higher Education Policy and Management, 39(4), 423-434.

Groen, J. A. (2004). The effect of college location on migration of college-educated labor. Journal of Econometrics, 121(1-2), 125-142.

Harrington, J. R., Munoz, J., Curs, B. R., \& Ehlert, M. (2016). Examining the impact of a highly targeted state administered merit aid program on brain drain: Evidence from a regression discontinuity analysis of Missouri's Bright Flight program. Research in Higher Education, 57(4), 423-447.

Hawley, Z. B., \& Rork, J. C. (2013). The case of state funded higher education scholarship plans and interstate brain drain. Regional Science and Urban Economics, 43(2), 242-249. 
Heller, D. E., \& Rasmussen, C. J. (2002). Merit scholarships and college access: Evidence from Florida and Michigan. In D. E. Heller \& P. Marin (Eds.), Who should we help? The negative social consequences of merit scholarships (pp. 25-40). Cambridge, MA: The Civil Rights Project at Harvard University.

Hickman, D. C. (2009). The effects of higher education policy on the location decision of individuals: Evidence from Florida's Bright Futures Scholarship Program. Regional Science and Urban Economics, 39(5), 553-562.

Holmes, W. M. (2013). Using propensity scores in quasi-experimental designs. Thousand Oaks, CA: Sage.

Ishitani, T. T. (2010). The determinants of outmigration among in-state college students in the United States. Research in Higher Education, 52(2), 107-122.

Kelchan, R., \& Webber, D. A. (2018). Examining the interstate mobility of recent college graduates. Educational Researcher, 47(3), 213-215.

Kodrzycki, Y. K. (2001). Migration of recent college graduates: Evidence from the National Survey of Youth. New England Economic Review, 13-34.

National Institutes of Health (NIH). n.d. Research Training and Career Development, National Institutes of Health, U.S. Department of Health \& Human Services, Washington, DC. Retrieved from https://researchtraining.nih.gov/resources/faq.

Normand, S. L. T., Landrum, M. B., Guadagnoli, E., Ayanian, J. Z., Ryan, T. J., Cleary, P. D., \& McNeil, B. J. (2001). Validating recommendations for coronary angiography following an acute myocardial infarction in the elderly: A matched analysis using propensity scores. Journal of Clinical Epidemiology, 54(4), 387398.

Perry, K. K. (2001). Where college students live after they graduate. ERIC Document Reproduction Service No. ED453739. National Center for Education Statistics, Washington, DC.

R Core Team (2015). R: A language and environment for statistical computing. R Foundation for Statistical Computing, Vienna, Austria. Retrieved January 10, 2018, from http://www.R-project.org/.

Rosenbaum, P. R., \& Rubin, D. B. (1983). The central role of the propensity score in observational studies for causal effects. Biometrika, 70(1), 41-55.

Rothwell, J. (2015). What colleges do for local economies: A direct measure based on consumption. Metropolitan Policy Program, Brookings Institution, Washington, DC.

Rubin, D. B. (1987). Multiple imputation for nonresponse in surveys. New York: Wiley.

Sekhon, J. S. (2011). Multivariate and propensity score matching software with automated balance optimization: The matching package for R. Journal of Statistical Software, 42(i07), 1-52. Retrieved January 10, 2018, from http://www.jstatsoft.org/v42/i07/.

Sinharay, S., Stern, H. S., \& Russell, D. (2001). The use of multiple imputation for the analysis of missing data. Psychological Methods, 6(4), 317-329.

Sjoquist, D. L., \& Winters, J. V. (2013). The effects of HOPE on post-college retention in the Georgia workforce. Regional Science and Urban Economics, 43(3), 479-490. 
U.S. Department of Education (2015). Residence and migration of all first-time degree/certificateseeking undergraduates in 4-year degree-granting postsecondary institutions who graduated from high school in the previous 12 months, by state or jurisdiction: Fall 2014 [Table]. Institute of Education Sciences, National Center for Education Statistics, U.S. Department of Education, Washington, DC. Retrieved January 10, 2018, from https://nces. ed.gov/programs/digest/d16/tables/dt16_309.30. asp?current=yes.

Winters, J. V. (2015). The production and stock of college graduates for U.S. states. Working Paper 15-246, W.E. Upjohn Institute for Employment Research, Kalamazoo, MI.

Zhang, L., \& Ness, E. C. (2010). Does state meritbased aid stem brain drain? Educational Evaluation and Policy Analysis, 32(2), 143-165. 